\title{
Disentangling the effects of insomnia and night work on cardiovascular diseases: a study in nursing professionals
}

\author{
A. Silva-Costa ${ }^{1}$, R.H. Griep ${ }^{2}$ and L. Rotenberg ${ }^{2}$ \\ ${ }^{1}$ Escola Nacional de Saúde Pública, Fundação Oswaldo Cruz (Fiocruz), Rio de Janeiro, RJ, Brasil \\ ${ }^{2}$ Laboratório de Educação em Ambiente e Saúde, Instituto Oswaldo Cruz (Fiocruz), Rio de Janeiro, RJ, Brasil
}

\begin{abstract}
Cardiovascular diseases (CVDs) are known to be associated with poor sleep quality in general populations, but they have not been consistently associated with specific work schedules. Studies of CVD generally do not simultaneously consider sleep and work schedules, but that approach could help to disentangle their effects. We investigated the association between insomnia and a self-reported physician diagnosis of CVD in day and night workers, considering all sleep episodes during nocturnal and diurnal sleep. A cross-sectional study was conducted in 1307 female nursing professionals from 3 public hospitals, using baseline data from the "Health and Work in Nursing - a Cohort Study." Participants were divided into two groups: i) day workers with no previous experience in night shifts $(n=281)$ and whose data on insomnia were related to nocturnal sleep and ii) those who worked exclusively at night $(n=340)$ and had data on both nocturnal and diurnal sleep episodes, as they often sleep at daytime. Multiple logistic regression analysis was performed. Among day workers, insomnia complaints increased the odds of CVD 2.79-fold (95\% Cl=1.01-6.71) compared with workers who had no complaints. Among night workers, reports of insomnia during both nocturnal and diurnal sleep increased the odds of reported CVD 3.07 -fold $(95 \% \mathrm{Cl}=1.30-7.24)$. Workers with insomnia had similar probabilities of reporting CVD regardless of their work schedule, suggesting a relationship to insomnia and not to night work per se. The results also highlighted the importance of including evaluation of all sleep episodes (diurnal plus nocturnal sleep) for night workers.
\end{abstract}

Key words: Cardiovascular diseases; Insomnia; Night work; Nurse; Sleep

\section{Introduction}

The association between cardiovascular diseases (CVDs) and sleep complaints, such as difficulty falling asleep, sleep maintenance, or duration is well documented in general populations $(1,2)$. Myocardial infarction, coronary heart disease, and stroke are related to sleep characteristics in the general population, as shown by epidemiological investigations of insomnia (1-3) and sleep duration (4).

CVDs are also thought to be associated with shift work (5-9) because of circadian stress caused by i) psychosocial mechanisms related to work stress, work-family conflicts, and the difficulty of recovering after work; ii) physiological mechanisms that influence inflammation, blood clotting, blood pressure, and activation of the autonomic nervous system and hypothalamic-pituitary-adrenal (HPA) axis; and iii) behavioral factors such as physical inactivity, weight gain, nutritional changes, smoking, and sleep duration and quality (10). All of these pathways have been linked directly or indirectly to sleep disturbances (11-14). For instance, a review of the association between insomnia and CVD shows that any deterioration in sleep quality or quantity may be associated with increases in nocturnal blood pressure and heart rate. Inflammation was proposed as a possible explanation for this association because sleep loss is associated with increased cellular inflammatory signaling (1).

Although the relationships between CVD and sleep complaints are well known in general populations, the influence of work schedules has not been widely evaluated. In this context, a specific characteristic of night workers is that they often sleep during the day. Therefore, the analysis of their sleep should include day sleep, not only because that is when they sleep, but also because diurnal sleep corresponds to a chronobiological challenge with possible health repercussions (15).

Studies of CVD that simultaneously investigate sleep complaints and work schedules could help to disentangle their effects; that is, determine whether the CVDs are related to night work per se, or whether the relationship is dependent on sleep complaints. The aim of this study was

Correspondence: A. Silva-Costa: <alinecos@ioc.fiocruz.br>.

Received March 13, 2014. Accepted July 22, 2014. First published online November 21, 2014. 
to investigate the association between complaints of insomnia and self-reported physician diagnosis of CVD in day- and night-shift nursing workers, considering all sleep episodes.

\section{Subjects and Methods}

This cross-sectional study was conducted in nursing professionals (i.e., nursing aides/assistants and registered nurses) from 3 public hospitals in Rio de Janeiro, Brazil $(\mathrm{N}=1509)$. Regarding the tasks carried out by nursing workers, nursing aides and assistants perform activities involving participation in nursing help, hygiene care, and patient comfort. According to Brazilian legislation, nursing aides and assistants can carry out their activities only with orientation and supervision provided by professional nurses. Nurses perform administrative functions, manage personnel and procedures, and care for seriously ill patients, including those whose condition requires knowledge of its scientific basis, performance of more complex procedures, or making immediate decisions.

All nursing workers (registered nurses, nursing aides/ assistants) who provided patient care were invited to participate. Only female workers $(n=1307)$ were included in the present analysis because of sex differences in sleep complaints (16). The procedures used to contact workers complied with ethical guidelines for conducting research with human subjects, as follows. The study was briefly explained to participants; they were informed that involvement was completely voluntary and that they could withdraw at any time with no negative ramifications. All participants signed the consent forms. The project was approved by the ethics committees of the Oswaldo Cruz Foundation and the participating hospitals.

Data were collected using a comprehensive questionnaire examining work-health relations among nursing personnel. Respondents were asked to provide information about their socio-demographic characteristics, physical and mental health symptoms, lifestyles, and management of time spent in nonprofessional activities (age, marital status, education degree, monthly income, smoking, physical activity, body mass index, sleep complaints, self-report of physician diagnosis of CVD, domestic work hours, professional work hours, professional category, time spent performing nursing activities, and number of working nights). The instrument also included scales evaluating psychosocial factors at work (demand-control and effort-reward imbalance). The questionnaire comprised two parts to accommodate the complexity of defining work schedules for nursing professionals due to the large number of workers holding two jobs in Brazilian hospitals $(17,18)$ and to changes in individual work schedules (19). For the first part, trained interviewers recorded information provided by participants, including insomnia complaints, to increase the accuracy of the data. The second part, which included the self-reported physician diagnosis of CVDs, was selfadministered after the interviewers explained the purpose of the research and provided instructions on how to complete the questionnaire $(17,18)$.

\section{Variable definitions and classification}

Work schedules. To exclude the possible influence of past experience with night work on insomnia complaints (18) all analyses of day workers only included workers with no previous night-work experience. This group was compared with those who worked only at night at the time of data collection. This procedure was designed to allow the comparison of homogeneous groups based on current work schedules (day or night only), regardless of the number of jobs held.

Interviewers asked the question "Do you regularly (at least once a week/4 times a month) work night shifts in nursing assistance somewhere?" to classify participants' work schedules at all jobs. The interviewers were instructed to define "regularly" as "at least once a week" when asking the question, and as "at least 4 times a month" for participants who considered their weekly schedules to be highly variable. The format of this question was based on the previously observed high variability of an individual worker's number of working nights, which may lead respondents to have difficulty defining the usual number of working nights (17). Participants who answered "yes" were considered current night workers, which is similar to the classification used by Marquié and Foret (20). Those who answered "no" were classified as day workers.

Day workers' previous experience with night work was defined using the question "Have you ever worked at night?" Possible answers were: i) yes, regularly, once a week; ii) yes, regularly, 2 or 3 times a week; iii) yes, regularly, 4 or more times a week; iv) yes, rarely; v) yes, occasionally; and vi) no. Participants who responded that they had regularly worked from 1 to 4 or more times per week were classified as former night workers. Those who responded that they had rarely, occasionally, or never worked at night were classified as day workers with no night-work experience. Previous night-work experience varied from less than 1 year to 26 years. Former night workers $(n=400)$ were excluded from the analysis, as were participants who worked during the day at one job and at night at the second job $(n=285)$. The study sample comprised data from nurses who worked during the day and had no previous experience in night work $(n=281)$ and those who worked only at night at the time of data collection $(n=340)$. There was one participant with missing data.

Self-reported physician diagnosis of CVD. CVDs were classified based on respondents' self-reports of a medical diagnosis of hypertension, coronary disease, myocardial infarction, or heart failure, as defined by the World Health Organization (WHO) (21). A report of at least one of these 
diseases diagnosed by a doctor was the criteria used to classify participants. As the question for CVD evaluation was the same for day and night workers and for workers with and without insomnia complaints, we do not expect that differences between the groups resulted from the way this information was obtained.

Insomnia complaints. All workers were asked about insomnia using the following questions: "In relation to your sleep during the night during the last 4 weeks at home, how often did you: i) have difficulty falling asleep?, ii) wake up and have difficulty going to sleep again?, and iii) wake up before the desired time and not manage to sleep again?" For all questions, the possible responses were: never/ rarely/sometimes (i.e., no sleep complaint) and almost always/always (i.e., sleep complaint). Respondents who reported any of the described sleep problems were assigned to the insomnia group (22-24). Thus, day workers were evaluated for nighttime sleep insomnia.

Moreover, considering that night workers often sleep during the day, the instrument for collecting data included questions about insomnia complaints relating to daytime sleep. The night workers thus answered the following questions: "In relation to your sleep during the day, before or after a night shift, during the last 4 weeks, how often did you...", with the same questions and response alternatives used for insomnia complaints related to nocturnal sleep. Thus, while day workers were evaluated for insomnia related to nocturnal sleep, night workers were evaluated for the presence or absence of insomnia episodes during sleep i) at night, ii) during the day, and iii) both nighttime and daytime.

The kappa statistic was used to assess the reliability of sleep variables. The kappa value for insomnia complaints among day workers was $0.63(95 \% \mathrm{Cl}=0.36$ 0.89 ), indicating substantial stability. For night workers, kappa values for nocturnal and diurnal insomnia complaints were $0.60(95 \% \mathrm{Cl}=0.38-0.82)$ and 0.50 $(95 \% \mathrm{Cl}=0.22-0.78)$, indicating substantial and moderate agreement, respectively (25).

\section{Data analysis}

Descriptive analyses of socio-demographic, lifestyle, and work-related variables were performed using the chisquare or Mann-Whitney test $(P<0.05)$. Tests were used to screen potential confounders, including age, race, smoking and alcohol habits, body mass index, physical activity, marital status, monthly family income, education level, professional and domestic work hours, professional category, time spent on nursing activities, number of jobs, demand-control and effort-reward imbalance (effortreward cutoff was the third tertile). Variables showing at least minimal association $(P<0.20)$ with the outcome and the exposure and variables described in the literature as potential confounders were selected for inclusion in multiple logistic regression models. The logistic regression was used to test the association between insomnia complaints and self-reporting of physician diagnosis of CVDs. All analyses were performed separately for day and night workers, with results reported as odds ratios (OR) and $95 \% \mathrm{Cl}$. The SPSS software (version 18.0; SPSS Inc., USA) was used for data analysis.

\section{Results}

Most workers were nursing aides/assistants (78.9\%). Professional nurses were younger than the nursing aides/ assistants (35.4 vs 38.2 years old; $P=0.032$ ) and had $a$ higher income (US\$498.80 vs US\$280.60; $\mathrm{P}<0.001$ ). The professional work hours $(P=0.278)$, domestic work hours $(P=0.828)$, number of jobs $(P=0.721)$, smoking habits $(P=0.125)$, and marital situation $(P=0.140)$ of professional nurses and nursing aides/assistants were not significantly different. Neither insomnia complaints nor CVDs were significantly different between professional nurses and nursing aides/assistants. The proportions of professional nurses and nursing aides/assistants did not differ between groups; therefore, the data for all workers within each group were combined for all analyses.

The mean $( \pm S D)$ age of workers was $37.6 \pm 13.2$ years. The average durations of nursing work were $10.7 \pm 11.4$ and $13.5 \pm 11.2$ years, and the average numbers of professional work hours worked per week were $40.5 \pm 12.1$ and $45.1 \pm 17.0$ for day and night workers, respectively. The prevalence of self-reported physician diagnosis of CVD was $18 \%$ among day workers and $21 \%$ among night workers. Nocturnal insomnia complaints were reported by $23 \%$ and $24 \%$ of day and night workers, respectively. The prevalence of diurnal sleep-related insomnia complaints was 35\% among night workers, $13 \%$ of whom reported both diurnal and nocturnal sleep-related insomnia complaints.

Table 1 shows that participants who reported CVDs were older, worked more hours per week (combined professional and domestic activities), and were more often overweight or obese than those who did not reported having a diagnosis of CVD.

Table 2 describes the socio-demographic and work characteristics of nursing workers with insomnia complaints. Among the day workers, 27\% reported CVDs; $35 \%$ of night workers with both day and night insomnia complaints reported CVDs, and $53.5 \%$ were classified in the group exposed to effort-reward imbalance. Night workers with complaints of day and night insomnia worked longer domestic hours than did those without complaints of day and night insomnia ( 24.5 and 17.8 hours, respectively).

The association between insomnia and self-reported CVD diagnosis was statistically significant after adjusting for socio-demographic, lifestyle, and work-related variables. Among day workers, nocturnal insomnia complaints increased the chances of self-reported physician diagnosis of CVDs 2.79 -fold $(95 \% \mathrm{Cl}=1.01-6.71) \mathrm{com}-$ pared with those with no insomnia complaints. Among 
Table 1. Sociodemographics, life style and work characteristics among nursing workers according to the prevalence of self-reported physician diagnosis of cardiovascular diseases (CVD).

\begin{tabular}{|c|c|c|c|}
\hline & \multicolumn{3}{|c|}{ Self-reported physician diagnosis of CVD } \\
\hline & No $(n=489)$ & Yes $(n=121)$ & Total \\
\hline Age $\left(\right.$ years) ${ }^{*}$ & $34.8 \pm 12.4$ & $49.1 \pm 9.92$ & $37.6 \pm 13.2$ \\
\hline Monthly family income (US\$) & $344.30 \pm 225.90$ & $323.80 \pm 247.10$ & $340.10 \pm 231.30$ \\
\hline Weekly domestic work hours* & $15.3 \pm 15.9$ & $25.8 \pm 18.1$ & $17.3 \pm 16.8$ \\
\hline Weekly professional work hours* & $43.8 \pm 15.4$ & $40.2 \pm 13.7$ & $43.8 \pm 15.1$ \\
\hline \multicolumn{4}{|l|}{ School education $(\%)^{*}$} \\
\hline Fundamental/high school & 40.1 & 63.3 & 44.7 \\
\hline College education & 59.9 & 36.7 & 55.3 \\
\hline Overweight/obese $(\%)^{*}$ & 37.4 & 65.5 & 43.1 \\
\hline Smoking habits (\%) & 10.6 & 15.7 & 11.6 \\
\hline Engaged in 2 or 3 jobs (\%) & 18.4 & 16.5 & 18.1 \\
\hline \multicolumn{4}{|l|}{ Marital status $(\%)^{*}$} \\
\hline Single & 44.6 & 23.1 & 40.3 \\
\hline Married/living with partner & 42.3 & 47.1 & 43.3 \\
\hline Divorced/separated/widowed & 13.1 & 29.8 & 16.4 \\
\hline \multicolumn{4}{|l|}{ Professional category (\%) } \\
\hline Registered nurses & 22.5 & 15.7 & 21.1 \\
\hline Nurse assistants/aides & 77.5 & 84.3 & 78.9 \\
\hline Time on nursing activities (years) ${ }^{*}$ & $9.9 \pm 10.8$ & $21.6 \pm 8.9$ & $12.3 \pm 11.4$ \\
\hline Number of working nights per 2-week span & $5.9 \pm 2.1$ & $5.8 \pm 2.2$ & $5.9 \pm 2.1$ \\
\hline Effort reward imbalance (\%) & 31.9 & 33.1 & 32.1 \\
\hline High demand and low control (\%) & 19.3 & 22.1 & 19.8 \\
\hline
\end{tabular}

Data are reported as means $\pm S D$ or otherwise indicated. ${ }^{*} \mathrm{P}<0.05$, statistically significant association (chi-square or Mann-Whitney test).

night workers, diurnal and nocturnal insomnia complaints increased the odds of self-reported physician diagnosis of CVDs $(\mathrm{OR}=3.07,95 \% \mathrm{Cl}=1.30-7.24$; Table 3$)$.

\section{Discussion}

In the present study, insomnia complaints were associated with self-reported physician diagnosis of CVDs among day workers. The same result was observed for night workers, provided that both diurnal and nocturnal sleep episodes were considered. It is noteworthy that these associations were adjusted for several confounding factors, including psychosocial aspects known to be related to CVD and insomnia.

The probability of self-reporting a physician diagnosis of CVD was similar for day and night workers with insomnia, suggesting that this was associated with insomnia and not to night work per se. This result helps to disentangle the relationships among insomnia, night work, and CVD.

Prospective epidemiological studies conducted in the general population have revealed associations between insomnia and CVD. Chien (26) found that the risk of developing CVD was 1.78-times greater in individuals who reported insomnia than in those who did not. Another recent study showed that complaints of difficulty falling asleep and maintaining sleep were associated with increases of $45 \%$ and $30 \%$, respectively, in the risk of acute myocardial infarction (27). Phillips and Mannino (28) observed that the risk of developing CVD was $50 \%$ greater in participants who had difficulty falling asleep, awoke repeatedly, and woke feeling tired than in those without such complaints. A review of insomnia and CVDs (1) pointed out that resting heart rates tend to be slightly elevated in individuals with insomnia, which can increase cardiovascular risk.

Night shifts and rotating shifts have been associated with several chronic diseases, including CVD (8). Nevertheless, the prevalence of CVD did not differ in day and night workers in the present study. Night workers are exposed both to cardiovascular risks common to the general population and to circadian misalignment due to the negative influence of night work on the cardiovascular system (10). Also, a higher prevalence of insomnia complaints among night workers compared to day workers would be expected because of the negative effect of night work on sleep (29-31). However, in this study, day and night workers did not differ with regard to night-sleep difficulties, confirming previous data gathered from nursing professionals (32). The similarity of night-sleep insomnia complaints in night- and day-shift workers is 


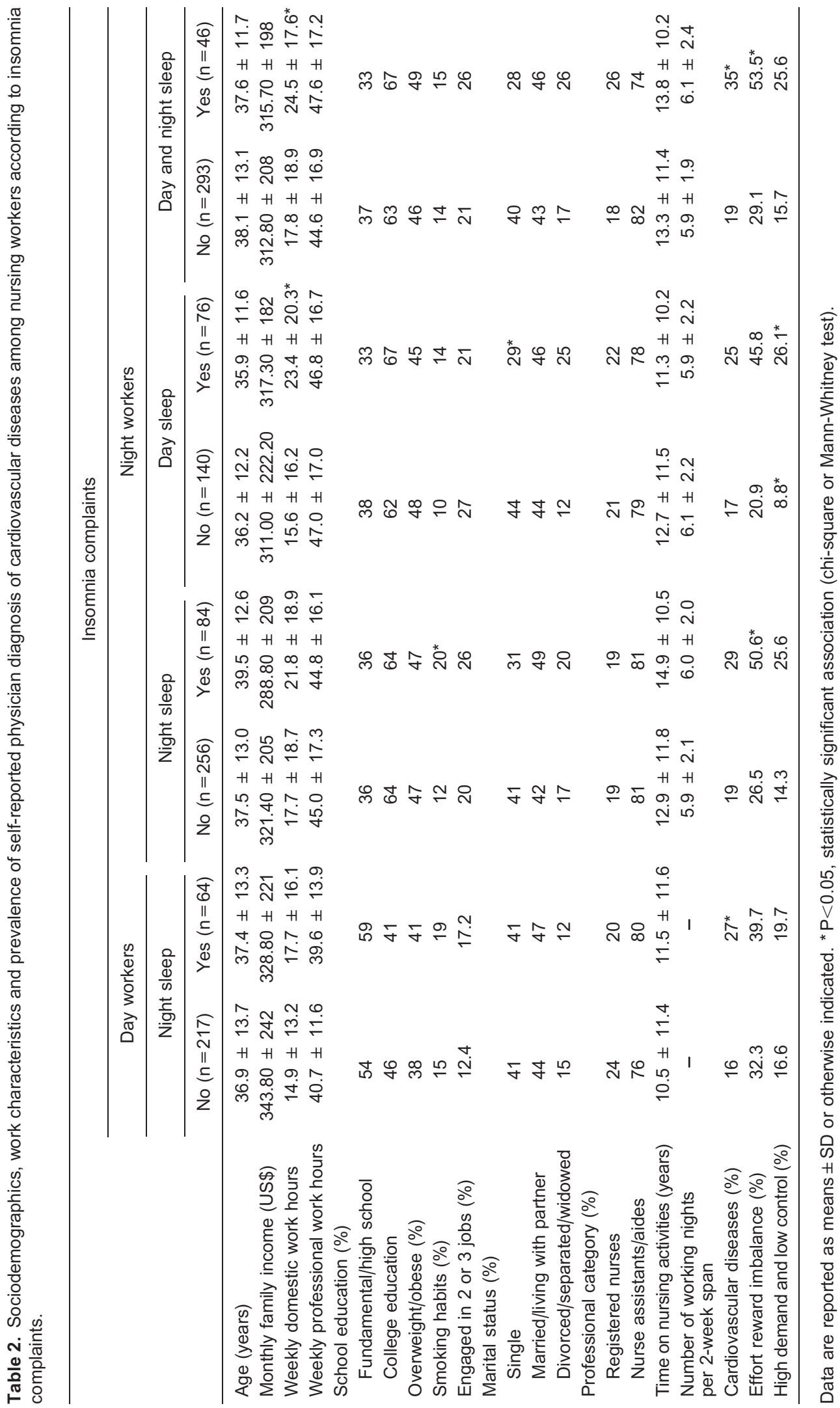


Table 3. Association between insomnia complaints and self-reported physician diagnosis of cardiovascular diseases among nursing professionals.

\begin{tabular}{|c|c|c|c|c|}
\hline \multirow[t]{2}{*}{ Work schedule } & \multirow[t]{2}{*}{ Insomnia complaint } & \multicolumn{3}{|c|}{ Self-reported physician diagnosis of CVD } \\
\hline & & $\begin{array}{l}\text { Model } 1 \text { Crude } \\
\text { OR }(95 \% \mathrm{Cl} \%)\end{array}$ & $\begin{array}{l}\text { Model } 2 \text { Adjusted } \\
\text { OR }(95 \% \mathrm{Cl})\end{array}$ & $\begin{array}{l}\text { Model } 3 \text { Adjusted } \\
\text { OR }(95 \% \mathrm{Cl})\end{array}$ \\
\hline \multirow[t]{2}{*}{ Day work } & No complaint concerning nocturnal sleep & 1 & 1 & 1 \\
\hline & Complaint concerning nocturnal sleep & $2.33(1.28-4.61)$ & 2.67 (1.04-6.88) & $2.79(1.01-6.71)$ \\
\hline \multirow[t]{6}{*}{ Night work } & $\begin{array}{l}\text { No complaint concerning both diurnal and } \\
\text { nocturnal sleep }\end{array}$ & 1 & 1 & 1 \\
\hline & $\begin{array}{l}\text { Complaint concerning both diurnal and } \\
\text { nocturnal sleep }\end{array}$ & $2.47(1.24-4.92)$ & $3.37(1.46-7.79)$ & $3.07(1.30-7.24)$ \\
\hline & No complaint concerning nocturnal sleep & 1 & 1 & 1 \\
\hline & Complaint concerning nocturnal sleep & $1.84(1.02-3.29)$ & $2.05(1.01-4.10)$ & $1.81(0.88-3.75)$ \\
\hline & No complaint concerning diurnal sleep & 1 & 1 & 1 \\
\hline & Complaint concerning diurnal sleep & $1.82(0.88-3.76)$ & $2.35(0.97-5.68)$ & $2.01(0.81-5.04)$ \\
\hline
\end{tabular}

Insomnia complaints refer to nocturnal and/or diurnal sleep episodes. Model 1: unadjusted model; Model 2: analysis adjusted for age, race, smoking habits, weekly domestic work hours, and body mass index; Model 3: analysis adjusted for model 2 plus work factors (weekly professional work hours and effort reward imbalance). CVD: cardiovascular diseases.

consistent with the findings of Akerstedt et al. (33) who conducted a questionnaire-based survey of a representative sample of the Swedish population. They reported that night-shift workers did not consider shift work as a major source of sleep disturbances, and observed that "their complaint levels bear no resemblance to those seen in insomniac patients". The authors argued that shift workers might not consider their sleep to be disturbed and that sleep disturbances may partly "be overlooked and/or considered part of the job" (33). In their study, the similarity of nocturnal-sleep insomnia complaints made by day- and night-shift workers may be explained by the exclusive analysis of night sleep, which is the most common study design.

Among night workers, the OR of self-reporting a physician diagnosis of CVD related to nocturnal sleep complaints $(\mathrm{OR}=1.81)$ was much smaller than that for both nocturnal and diurnal sleep $(O R=2.79)$. The findings of this study reveal the importance of not restricting the analyses of insomnia to nocturnal sleep in the case of night workers. Moreover, in that group, the higher prevalence of day- compared with night-sleep insomnia complaints $(35 \%$ vs $24 \%)$ shows that the exclusive analysis of complaints referring to night sleep does not capture the entire impact of work schedules and highlights the relevance of considering all sleep episodes. This importance stems from the fact that night workers often sleep during the day and are also exposed to difficulties of a chronobiological nature, with health implications (15).

A potential biological explanation for the association of insomnia and sleep debt with cardiovascular risks (34) is related to an association of insomnia with both glucose metabolism disorders and high blood pressure. This relationship cannot be described as a linear cascade; rather, it is a complex, multifactorial process involving a neuro-endocrine-metabolic network (35). Several studies have shown that sleep deprivation increases sympathetic nervous system activity, leading to increased blood pressure and heart rate $(36,37)$. Inflammation is also pointed out as a possible explanation for this association (1). Meier-Ewert (38) reported that inadequate sleep might increase the risk of CVD in apparently healthy individuals due to the activation of inflammatory processes, which could contribute to the association between sleep complaints and cardiovascular morbidity. Furthermore, the combined effects of overtime work and insufficient sleep may critically increase nervous system activity, potentially inducing acute myocardial infarction (39).

Several limitations of this study should be considered. First, it did not examine the direction of causality in the association between sleep problems and cardiovascular outcomes; a reverse causality is possible. Barone and Menna-Barreto (35) described the interaction of diabetes, which is strongly associated with cardiovascular risk, and sleep as a vicious cycle. Second, although the analyses performed in this study were adjusted for potential confounding factors, the possibility of residual effects or those of uncontrolled variables cannot be excluded. Third, because CVDs were evaluated on the basis of selfreported medical diagnoses, the data were subject to reporting bias. However, this bias was not expected to differ between day and night workers. Metabolic diseases, immune system disorders, and depression, all of which could influence the relations between the studied exposure and the outcome were not investigated. Also, the prevalence of both CVD and insomnia complaints observed in this study may have been influenced by the "healthy worker effect", in which there is a selection of those more tolerant to work and who tend to be healthier (15). Finally, the data collection instrument used in this 
study included work-related factors, questions about professional work hours, and two psychosocial scales (demand-control and effort-reward imbalance). As argued by McNeely (40), studies that investigate the health effects of nurses' work typically measure only physical or psychological demands, resulting in underestimations. In the present study, other organizational and psychosocial aspects that were not considered may have influenced the results.

Studies of the relationship between shift work and cardiovascular risk face the difficulty of accounting for heterogeneity of individual work schedules and the number of working nights per week (9). In the present study, night workers worked exclusively at night and day workers had no previous night work experience. This distinction reduced heterogeneity among workers and constitutes a study strength.

In sum, this study has two main contributions. First, it demonstrates the relevance of evaluating sleep according to work shift and sleep pattern (nocturnal and/or diurnal episodes), which has not been previously reported in the

\section{References}

1. Spiegelhalder K, Scholtes C, Riemann D. The association between insomnia and cardiovascular diseases. Nat Sci Sleep 2010; 2: 71-78, doi: 10.2147/NSS.S7471.

2. Ohayon MM. Observation of the natural evolution of insomnia in the American general population cohort. Sleep Med Clin 2009; 4: 87-92, doi: 10.1016/j.jsmc.2008.12.002.

3. Sofi F, Cesari F, Casini A, Macchi C, Abbate R, Gensini GF. Insomnia and risk of cardiovascular disease: a metaanalysis. Eur J Prev Cardiol 2014; 21: 57-64, doi: $10.1177 / 2047487312460020$.

4. Meisinger $C$, Heier $M$, Lowel $H$, Schneider $A$, Doring $A$. Sleep duration and sleep complaints and risk of myocardial infarction in middle-aged men and women from the general population: the MONICA/KORA Augsburg cohort study. Sleep 2007; 30: 1121-1127.

5. Knutsson A. Health disorders of shift workers. Occup Med 2003; 53: 103-108, doi: 10.1093/occmed/kqg048.

6. Fujino $\mathrm{Y}$, Iso H, Tamakoshi A, Inaba Y, Koizumi A, Kubo T, et al. A prospective cohort study of shift work and risk of ischemic heart disease in Japanese male workers. Am J Epidemiol 2006; 164: 128-135, doi: 10.1093/aje/kwj185.

7. Tuchsen F, Hannerz H, Burr H. A 12 year prospective study of circulatory disease among Danish shift workers. Occup Environ Med 2006; 63: 451-455, doi: 10.1136/oem. 2006.026716.

8. Wang XS, Armstrong ME, Cairns BJ, Key TJ, Travis RC. Shift work and chronic disease: the epidemiological evidence. Occup Med 2011; 61: 78-89, doi: 10.1093/occmed/kqr001.

9. Leclerc A. Shift-work and cardiovascular disease. Eur $J$ Epidemiol 2010; 25: 285-286, doi: 10.1007/s10654-0109456-2.

10. Puttonen S, Harma M, Hublin C. Shift work and cardiovascular disease - pathways from circadian stress to morbidity. Scand J Work Environ Health 2010; 36: 96-108, doi: literature. Second, workers with insomnia have similar chances of reporting CVD regardless of their work schedule, thus suggesting that this is related to insomnia and not to night work per se. Finally, the study indicates that sleep disturbance is a public health problem that deserves to be better understood and addressed by both policymakers and workers themselves. As insomnia is the most common sleep complaint, our findings highlight the importance of considering all sleep episodes on the investigation and treatment of insomnia in patients with CVD.

\section{Acknowledgments}

Research supported by CNPq and FAPERJ. L. Rotenberg and R.H. Griep are Irving Selikkoff International Fellows of the Mount Sinai School of Medicine ITREOH Program. Their work was supported in part by Grant 1 D43 TW00640 from the Fogarty International Center of the National Institutes of Health.

10.5271/sjweh.2894.

11. Kivimaki $M$, Virtanen $M$, Elovainio $M$, Kouvonen $A$, Vaananen A, Vahtera J. Work stress in the etiology of coronary heart disease - a meta-analysis. Scand J Work Environ Health 2006; 32: 431-442, doi: 10.5271/sjweh.1049.

12. Eller NH, Netterstrom B, Gyntelberg F, Kristensen TS, Nielsen F, Steptoe A, et al. Work-related psychosocial factors and the development of ischemic heart disease: a systematic review. Cardiol Rev 2009; 17: 83-97, doi: 10.1097/CRD.0b013e318198c8e9.

13. Boggild $H$, Knutsson $A$. Shift work, risk factors and cardiovascular disease. Scand J Work Environ Health 1999; 25: 85-99, doi: 10.5271/sjweh.410.

14. Spiegel K, Tasali E, Penev P, Van Cauter E. Brief communication: Sleep curtailment in healthy young men is associated with decreased leptin levels, elevated ghrelin levels, and increased hunger and appetite. Ann Intern Med 2004; 141: 846-850, doi: 10.7326/0003-4819-141-11200412070-00008.

15. Costa G. Saúde e trabalho em turnos e noturno. In: Fischer FM, Moreno CRC, Rotenberg L (Editors), Trabalho em turnos e noturno na sociedade 24 horas. São Paulo: Atheneu; 2004.

16. Krishnan V, Collop NA. Gender differences in sleep disorders. Curr Opin Pulm Med 2006; 12: 383-389, doi: 10.1097/01.mcp.0000245705.69440.6a.

17. Rotenberg L, Griep RH, Fischer FM, Fonseca MJ, Landsbergis $P$. Working at night and work ability among nursing personnel: when precarious employment makes the difference. Int Arch Occup Environ Health 2009; 82: 877885, doi: 10.1007/s00420-008-0383-4.

18. Rotenberg L, Silva-Costa A, Diniz TB, Griep RH. Long-term deleterious effects of night work on sleep. Sleep Sci 2011; 4: 13-20. 
19. Ribeiro-Silva F, Rotenberg L, Soares RE, Pessanha J, Ferreira FL, Oliveira $P$, et al. Sleep on the job partially compensates for sleep loss in night-shift nurses. Chronobiol Int 2006; 23: 1389-1399, doi: 10.1080/07420520601091931.

20. Marquie JC, Foret J. Sleep, age, and shiftwork experience. J Sleep Res 1999; 8: 297-304, doi: 10.1046/j.13652869.1999.00170.x.

21. World Health Organization (WHO). Cardiovascular diseases. http://www.who.int/topics/cardiovascular_diseases/ en/index.html.

22. Ohayon MM. Epidemiology of insomnia: what we know and what we still need to learn. Sleep Med Rev 2002; 6: 97-111, doi: 10.1053/smrv.2002.0186.

23. Pires ML, Benedito-Silva AA, Mello MT, Del Giglio S, Pompeia C, Tufik S. Sleep habits and complaints of adults in the city of Sao Paulo, Brazil, in 1987 and 1995. Braz J Med Biol Res 2007; 40: 1505-1515, doi: 10.1590/S0100-879X 2006005000170.

24. Robaiana JR, Lopes CS, Rotenberg L, Faerstein E, Fischer FM, Moreno CRC, et al. Stressful life events and insomnia complaints among nursing assistants from a university hospital in Rio de Janeiro: The Pro-Saude Study. Rev Bras Epidemiol 2009; 12: 501-509, doi: 10.1590/S1415$790 \times 2009000300018$.

25. Landis JR, Koch GG. The measurement of observer agreement for categorical data. Biometrics 1977; 33: 159174, doi: 10.2307/2529310.

26. Chien KL, Chen PC, Hsu HC, Su TC, Sung FC, Chen MF, et al. Habitual sleep duration and insomnia and the risk of cardiovascular events and all-cause death: report from a community-based cohort. Sleep 2010; 33: 177-184.

27. Laugsand LE, Vatten LJ, Platou C, Janszky I. Insomnia and the risk of acute myocardial infarction: a population study. Circulation 2011; 124: 2073-2081, doi: 10.1161/CIRCULA TIONAHA.111.025858.

28. Phillips B, Mannino DM. Do insomnia complaints cause hypertension or cardiovascular disease? J Clin Sleep Med 2007; 3: 489-494.

29. Niedhammer I, Lert F, Marne MJ. Effects of shift work on sleep among French nurses. A longitudinal study. J Occup Med 1994; 36: 667-674.

30. Pires ML, Teixeira CW, Esteves AM, Bittencourt LR, Silva
RS, Santos RF, et al. Sleep, ageing and night work. Braz J Med Biol Res 2009; 42: 839-843, doi: 10.1590/S0100879X2009005000011.

31. Rajaratnam SM, Howard ME, Grunstein RR. Sleep loss and circadian disruption in shift work: health burden and management. Med J Aust 2013; 199: S11-S15, doi: 10.5694/mja13.10561.

32. Portela LF, Rotenberg L, Waissmann W. Self-reported health and sleep complaints among nursing personnel working under $12 \mathrm{~h}$ night and day shifts. Chronobiol Int 2004; 21: 859-870, doi: 10.1081/CBI-200038513.

33. Akerstedt T, Ingre M, Broman JE, Kecklund G. Disturbed sleep in shift workers, day workers, and insomniacs. Chronobiol Int 2008; 25: 333-348, doi: 10.1080/ 07420520802113922

34. Nilsson PM, Nilsson JA, Hedblad B, Berglund G. Sleep disturbance in association with elevated pulse rate for prediction of mortality - consequences of mental strain? J Intern Med 2001; 250: 521-529, doi: 10.1046/j.13652796.2001.00913.x.

35. Barone MT, Menna-Barreto L. Diabetes and sleep: a complex cause-and-effect relationship. Diabetes Res Clin Pract 2011; 91: 129-137, doi: 10.1016/j.diabres.2010.07.011.

36. Lusardi P, Zoppi A, Preti P, Pesce RM, Piazza E, Fogari R Effects of insufficient sleep on blood pressure in hypertensive patients: a 24-h study. Am J Hypertens 1999; 12: 6368, doi: 10.1016/S0895-7061(98)00200-3.

37. Tochikubo O, Ikeda A, Miyajima E, Ishii M. Effects of insufficient sleep on blood pressure monitored by a new multibiomedical recorder. Hypertension 1996; 27: 13181324, doi: 10.1161/01.HYP.27.6.1318.

38. Meier-Ewert HK, Ridker PM, Rifai N, Regan MM, Price NJ, Dinges DF, et al. Effect of sleep loss on C-reactive protein, an inflammatory marker of cardiovascular risk. J Am Coll Cardiol 2004; 43: 678-683, doi: 10.1016/j.jacc.2003.07.050.

39. Liu Y, Tanaka H. Overtime work, insufficient sleep, and risk of non-fatal acute myocardial infarction in Japanese men. Occup Environ Med 2002; 59: 447-451, doi: 10.1136/ oem.59.7.447.

40. McNeely E. The consequences of job stress for nurses' health: time for a check-up. Nurs Outlook 2005; 53: 291 299, doi: 10.1016/j.outlook.2005.10.001. 